\title{
DEVELOPMENT OF OVERWEIGHT PERMIT FEE USING MECHANISTIC-EMPIRICAL PAVEMENT DESIGN AND LIFE-CYCLE COST ANALYSIS
}

\author{
Hao Wang, Jingnan Zhao \\ Dept of Civil and Environmental Engineering, Rutgers University, Piscataway, United States
}

Submitted 1 May 2015; resubmitted 23 July 2015, accepted 6 September 2015

\begin{abstract}
The study aims to determine rational overweight permit fee using Mechanistic-Empirical (M-E) pavement design and Life-Cycle Cost Analysis (LCCA). The state-of-art pavement design software, Pavement-ME, was utilized to develop Load Equivalency Factors (LEFs) and estimate pavement service life under various traffic loading conditions. LCCA was conducted to calculate Marginal Pavement Damage Cost (MPDC) in terms of Equivalent Uniform Annual Cost (EUAC) considering variations in maintenance strategies, analysis periods, and discount rates. A methodology framework was established to calculate distance based, weight based, weight and distance based, and flat permit fee for overweight trucks. With the local data obtained in New Jersey (United States), example permit fees were determined for the major and local road network with the thick and thin asphalt pavement structure, respectively. It was found that the truck-induced damage cost varied significantly between thin and thick asphalt pavements considering different failure mechanisms in fatigue cracking and rutting. In general, overweight permit fee may not be fair to overweight trucks at different vehicle classifications if only the total overweight tonnage is regulated in the permit fee structure.
\end{abstract}

Keywords: truck; permit fee; pavement damage; life-cycle cost; overweight.

\section{Introduction}

Traffic loading on road pavements is characterized by a number of different types of vehicles with variations in Gross Vehicle Weight (GVW), axle configuration, and axle loading. For the purposes of infrastructure preservation and traffic safety, trucking operational characteristics (i.e., size and weight) is regulated using federal and state legislation and policies. However, overweight trucks are frequently observed on highways since vehicle user cost can be reduced through transporting commodity using overweight trucks in fewer trips. Overweight truck traffic may reduce the total traffic volume and traffic congestion, but increase pavement maintenance costs and frequency of pavement repair. Therefore, highway agencies seek reliable knowledge of the fraction of damage caused to the pavement by heavy vehicles to serve as a basis for establishing an efficient and equitable road user cost system.

Overweight permits help regulate the operation of overweight trucks by controlling damage to pavements and bridges while promoting commerce and the movement of goods and services. Based on the period of validity, overweight permits can be sorted into single use, multiple use, monthly use, seasonal use, and annual use. In practice, overweight vehicle permit fees are grouped into five structures: flat, weight-based, distance-based, weight and distance-based, and axle-based. Each permit fee structure has its unique advantages and challenges regarding fairness, precision allocation, and implementation complexity (Adams et al. 2013).

The increasing axle load and/or total vehicle weight shortens pavement service life and increases agency cost to maintain pavement condition at an acceptable level. Commonly identified pavement distress associated with heavy vehicles can be characterized as fatigue cracking and rutting. It is expected that the impact of overweight truck on pavement service life is affected by pavement structure, traffic characteristics, and overweight percentage. Thus, an appropriate methodology of determining rational permit fee for overweight trucks is required to recover the extra pavement damage cost caused by overloading on highway. It is expected that by doing so, highway agencies can be placed in a better position to preserve investments in highway infrastructure without sacrificing the competitive position of truck freight transportation. 


\section{Objective}

The study aims to determine rational overweight permit fee using Mechanistic-Empirical (M-E) pavement design and Life-Cycle Cost Analysis (LCCA). The state-of-art pavement design software, Pavement-ME, was utilized to develop Load Equivalency Factors (LEFs) and estimate pavement service life under various traffic loading conditions. LCCA was conducted to calculate Marginal Pavement Damage Cost (MPDC) in terms of Equivalent Uniform Annual Cost (EUAC) of considering variations in maintenance strategy, analysis period, and discount rate. With the local data obtained in New Jersey (United States), example permit fees were determined for the major and local road network with thick and thin asphalt pavement structures, respectively.

\section{Review of Relevant Studies}

Past studies have used field data or theoretical analysis for quantification of pavement damage caused by truck loading. These studies seek to estimate either the Average Pavement Damage Cost (APDC) or the MPDC. The average cost is the total maintenance and repair cost divided by the total road usage (such as the number of Equivalent Single Axle Loads (ESALs)); while the marginal cost is damage cost caused by an additional road usage on the pavement.

Hajek et al. (1998) explored power functions to establish relationship between EUAC and the common logarithm of the annual ESALs, respectively, for new pavements and in-service pavements. The marginal pavement costs per ESAL per year for new pavement were found from $\$ 0.0025$ to $\$ 0.5968$; while for in-service pavement from $\$ 0.0013$ to $\$ 0.307$ (Canadian dollars). Ahmed (2012) developed linear relationship between pavement damage costs and the nature logarithm of average annual ESALs. Pavement types (flexible pavement and rigid pavement) and pavement ages ranging from 0 to 50 years were the optional parameters in the final functions. It was found that MPDC per ESAL-mile was in the range of $\$ 0.0033$ on interstate highways to $\$ 0.1157$ on non-national highway systems.

The critical element of allocating pavement damage cost is developing truck fleet without overloading, and loads of manners were utilized in the prior studies. Hewitt et al. (1999) explored a procedure to quantify pavement damage and economic impacts due to regulation changes related to truck weights in Montana. Instead of existing vehicle fleet, based on several sources of information from Montana Motor Carries Associations (MMCA), a new traffic stream was created to estimate the changes of truck traffic volume and Vehicle Miles Traveled (VMT) for Montana highway network. The AASHTO design method and EUAC were utilized to calculate pavement performance and costs, and the ESAL and cost changes were plotted in term of percentage. The transportation costs of the 12 selected commercial industries were evaluated under the assumption of hauling the same amount of freight, which provided a truck productivity comparison between various sectors.
Chowdhury et al. (2013) performed a research to estimate pavement deterioration caused by overweight trucks and study the adequacy of standard permitting practices in state agencies. The additional pavement damage costs due to overweight trucks were estimated based on the increased pavement design thickness using the AASHTO 1993 method (AASHTO 1993). Three traffic scenarios were created: no trucks in the traffic (minimum design scenario), traffic includes trucks but no weights exceeding legal weight limits, and traffic includes trucks where $8.3 \%$ of trucks were overweight.

Tirado et al. (2010) derived the permit fee using pavement performance predicted using pavement responses predicted from the finite element model and M-E distress models. A parametric study was conducted to evaluate the effects of GVW and axle configurations, threshold to rehabilitation, traffic volume, and pavement structure on the cost of the permit fee. The analysis was based on the cost comparison between the standard truck and the overload truck with specific axle configurations.

Prozzi et al. (2012) conducted a comprehensive overweight/oversize truck study for Texas Department of Transportation considering pavement, bridge, and safety cost. The associate revenue from old and new permit fee structure was compared to the pavement and bridge consumption and operational and safety impact cost.

Banerjee et al. (2013) presented a methodology for determination of the load equivalencies for various axle and load configurations on flexible pavements using the DARwin-ME. It was found that except in the case of rutting, there was no evidence that Equivalent Damage Factors (EDFs) are affected by the structural capacity of the pavement sections. An example of applying the EDF into overweight vehicles was presented to show the effect of axle configuration on pavement damage.

However, some previous studies used the empirical relationships developed from road test results in developing equivalencies between pavement damage induced by different trucks, which did not consider the impact of loading on specific pavement failure mechanisms, such as fatigue cracking and rutting. Few studies investigated the impact of overweight vehicles on pavement damage considering the detailed traffic characteristics, such as truck class classification and axle configurations.

This study aims to accurately quantify the effect of vehicular loading on pavement deterioration using the traffic data measured using the Weigh-In-Motion (WIM). The recent advancement in the M-E Pavement Design Guideline (MEPDG) was adopted in the analysis. Although several studies have used the M-E based framework for overload analysis, the utilization of the newest pavement design guide would provide more confidence for agency using the derived fee structure. In particular, the MPDC function was derived to reflect the variation of pavement damage cost at different levels of traffic loading. The factors considered in this study is important for quantification of permit fee because the pavement damage cost caused by on additional pass 
of truck varies depending on pavement structure and traffic characteristics. The goal of study is to help state agencies more reliably assess the relative cost shares of damage caused by heavy weight vehicles and allocate resources for pavement maintenance and repair.

\section{Mechanistic-Empirical Pavement Analysis}

Roadway is designed to carry traffic loading with sufficient structure capacity for long life and smooth surface for ride comfortability. High skid resistance on pavement surface is desired to enhance road safety management (Dell'Acqua et al. 2011). The roadway design criteria are different for major highway and low-volume roads considering different geometric alignments, traffic loading, pavement structures, and environmental conditions (Dell'Acqua, Russo 2011; Dell'Acqua et al. 2012; Wang, Al-Qadi 2010; Wang et al. 2013; Žilionienè et al. 2013).

M-E pavement design methods represent onestep forward from empirical design methods. In the M-E pavement analysis, pavement responses (strains and stresses) under traffic loading are predicted using mechanistic models, and then empirical distress models are applied to establish proper correlation between pavement responses and long-term pavement performance (TRB 2004). In this study, the state-of-art M-E pavement design software, Pavement-ME v1.0, were used to estimate pavement service life under various traffic loading conditions.

Two typical pavement structures that are used in New Jersey highway system were selected for analysis, as shown in Table 1. For the asphalt concrete layer, dynamic modulus test data of typical asphalt mixtures were obtained from a previous study (Bennert 2009). Typical material properties were used for cement concrete and granular base layer with crushed stone. Soil properties were estimated from the soil's AASHTO group classifications.

WIM devices can continuously capture and record axle load, GVW and axle spacing with supplementary data such as date, time, speed, lane of travel, vehicle type, etc., over a measurement site. The common WIM technologies include piezoelectric sensor, quartz sensor, bending plate system, and single load cell. The installation cost of WIM varies from $\$ 10 \mathrm{k}$ to $\$ 50 \mathrm{k}$, depending on the sensor type (Zhang 2007). The WIM data at In- terstate Highway 78 (I-78) and New Jersey state highway 55 (NJ-55) were selected for traffic input of typical major road and minor road. One-year WIM data in 2010 was used in the analysis. The Annual Average Daily Truck Traffic (AADTT) for I-78 and NJ-55 are 11739 with 17\% overweight trucks and 1348 with $11 \%$ overweight truck in 2010, respectively. A linear growth rate of $3 \%$ was assumed for traffic increase. Other traffic input including axles per truck, monthly adjustment factors, and hourly distribution factors were obtained through the post-processing of WIM data at the selected two sites using selfdeveloped codes. In order to determine the pavement life under various loading scenarios, the AADTT and the percentage of overweight truck were varied with the same axle load spectrum from the WIM measurement.

In the Pavement-ME, environmental conditions are simulated by the Enhanced Integrated Climatic Model (EICM). The EICM model was developed in National Cooperative Highway Research Program (NCHRP) NCHRP 01-37A project that includes a database of approximately 800 weather stations throughout the US (TRB 2004). In this study, the weather station at Newark, NJ was used and no further local calibration was conducted. The computed temperature and moisture profiles from the EICM are combined with the input material properties to predict the daily and seasonal variations of asphalt layer modulus and subgrade moisture condition. The design criteria used in the analysis are $10 \%$ bottom-up fatigue cracking and 0.25 -inch rutting in the asphalt layer.

\section{Marginal Pavement Damage Cost}

\subsection{Life-Cycle Cost Analysis}

LCCA is a process for evaluating the long-term economic worth of a pavement project by calculating initial costs and discounted future costs. Agency costs and user costs are two major parts in LCCA. Agency costs are defined all the costs related to the owning organizations over the life of the project segment, such as initial construction costs and maintenance costs. User costs include travel time, vehicle operation, accidents and environmental costs induced on road users. In this study, only agency costs were considered in the pavement LCCA for permit fee determination.

Table 1. Representative pavement structures used for analysis

\begin{tabular}{|l|l|l|c|}
\hline \multicolumn{1}{|c|}{ Pavement type } & \multicolumn{1}{|c|}{ Layer type } & \multicolumn{1}{c|}{ Material } & Thickness [inches] \\
\hline \multirow{4}{*}{$\begin{array}{l}\text { Thick flexible } \\
\text { pavement }\end{array}$} & Surface course & Asphalt concrete (PG 76-22) & 6 \\
\cline { 2 - 4 } & Binder course & Asphalt concrete (PG 64-22) & 6 \\
\cline { 2 - 4 } & Base layer & Crushed gravel & Semi-infinite \\
\cline { 2 - 4 } & Subgrade & A-1 soil & 2 \\
\hline \multirow{4}{*}{$\begin{array}{l}\text { Thin flexible } \\
\text { pavement }\end{array}$} & Surface course & Asphalt concrete (PG 64-22) & 2 \\
\cline { 2 - 4 } & Binder course & Asphalt concrete (PG 64-22) & 20 \\
\cline { 2 - 4 } & Base layer & Crushed gravel & Semi-infinite \\
\cline { 2 - 4 } & Subgrade & A-1 soil & \\
\hline
\end{tabular}


The Net Present Value (NPV) of agency cost during the analysis period is computed using the discounted monetary value of future costs and salvages by transforming costs occurring in different time periods and salvages at the end of analysis period to a common unit of measurement - Eqs (1-2). EUAC represents the NPV assuming that the costs occur uniformly over the entire analysis period -Eq. (3).

$$
\begin{aligned}
& N P V=C+\sum_{i=1}^{k} M_{i} \cdot\left(\frac{1}{1+r}\right)^{n_{i}}-S \cdot\left(\frac{1}{1+r}\right)^{N} ; \\
& S=\left(1-\frac{L_{A}}{L_{E}}\right) \cdot C_{s},
\end{aligned}
$$

where: $N P V$ is Net Present Value or net present worth; $C$ is present cost of initial rehabilitation activity; $r$ is discount rate; $M_{i}$ is cost of the $i$-th maintenance and rehabilitation (M\&R) activity in terms of constant dollars; $n_{i}$ is number of years from the present to the $i$-th M\&R activity; $S$ is salvage value (or residual value) at the end of the analysis period; $L_{A}$ is difference between the year of the last maintenance activity and the year of termination of the life cycle analysis; $L_{E}$ is expected life of the maintenance activity; $C_{s}$ is cost of the maintenance activity having salvage value; $N$ is length of the analysis period in years.

$$
E U A C=N P V \cdot\left(\frac{r \cdot(1+r)^{N}}{(1+r)^{N}-1}\right),
$$

where: EUAC is Equivalent Uniform Annual Costs; $r$ is discount rate; $N$ is analysis period.

The analysis period and discount rate are two most important factors affecting the life-cycle cost. The analysis period should be selected to be sufficiently long to include pavement rehabilitation treatments but not so long that it becomes unreasonable (Walls, Smith 1998). According to National Cooperative Highway Research Program (NCHRP) Guide for Pavement-Type Selection, an analysis period of at least 40 years was suggested for new construction or reconstruction of pavements, while an analysis period of at least 30 years was suggested for rehabilitation of pavements (Hallin et al. 2011). A respectively longer analysis period should be selected for long-life pavements. Discount rate is used to convert future costs to present year costs. Historically discount rates are in the range of $3 \%$ to $5 \%$. The long-term real discount rate values supplied in the lately updated edition of the Office of Management and Budget (OMB) Circular A-94 was suggested to for LCCA (OMB 1992). The current long-term real discount rate is approximately $2 \%$. In this study, sensitivity analysis was performed to evaluate the effects of LCCA parameters on the life-cycle cost, considering analysis periods of 30 and 60 years and discount rates of $2 \%$ and $5 \%$.

Two pavement maintenance strategies, rehabilitation and reconstruction, were considered in the analysis. A typical rehabilitation strategy of milling to a depth of two inches and overlaying with two inches of new as- phalt concrete was used by the New Jersey Department of Transportation. It is assumed that the successive overlays will be placed and the service life of each overlay equals to half of the service life of the initial construction based on pavement performance data. For full reconstruction, it is reasonable to assume that the service life of each reconstruction is the same as the service life for the initial construction.

Maintenance costs for milling and overlay and full reconstruction were calculated using the cost formula proposed in a previous study for the NJDOT (Zaghloul et al. 2006). The unit cost (\$/square yard) equations used for flexible pavements are shown in Eqs (4-5), which are the total project cost including mobilization, material, labor costs:

$$
\begin{aligned}
& \text { Mill+ overlay: } 3.98 \cdot M+7.0 \cdot T_{a c} \\
& \text { Full reconstruction: } 65.71+7.0 T_{a c},
\end{aligned}
$$

where: $M$ is thickness of milling [inches]; $T_{a c}$ is thickness of asphalt concrete overlay [inches].

\subsection{Load Equivalency Factor}

Pavement deterioration is caused by distribution of the GVW on axles, so it is important to quantify the effect of individual axle configurations on pavement damage. Although the effects of axle load spectra on pavement damage can be quantified using M-E pavement analysis, standard traffic variable is still needed for road-use measurement. Historically, LEFs have been derived from the AASHO Road Test in the 1950s to convert different axle configurations to ESALs (AASHTO 1993). However, these LEFs were developed for a limited number of pavement types, load magnitudes, pavement ages, and environments and thus cannot reflect the recent developments in pavement material and structure design.

In order to accurately compare pavement damage caused by different axle types (single, tandem, tridem, and quad) and load magnitudes, LEFs were calculated from M-E pavement analysis for the pavement structures considered in this study. The LEF was defined as the ratio between the damage caused by one single pass of the axle in consideration and the damage caused by one single pass of the standard 18-kip single axle load with dual tires (one ESAL), as shown in Eq (6). The allowable number of load repetitions to failure is calculated from the MEPDG and it is defined as the number of axle loading passes causing pavement performance deterioration reaching the failure threshold (10\% bottom-up fatigue cracking and 0.25 -inch rutting). The calculated LEFs were used to determine the equivalent number of ESALs for each specific axle that will provide the basis for allocation of pavement damage cost.

$$
L E F=\frac{1 / N}{1 / N_{E S A L}}=\frac{N_{E S A L}}{N},
$$

where: $L E F$ is Load Equivalency Factor; $N_{E S A L}$ is allowable number of load repetitions to failure under the loading of the standard 18 kip single axle load with dual 
tires; $N$ is allowable number of load repetitions to failure under the loading of the axle with different load magnitudes and configurations.

It is expected that the failure mechanism of pavement varies depending on structure, material, traffic loading, and environment. The selection of LEF should depend on the predominant failure criteria encountered in the pavement. The M-E pavement analysis in this study showed that thick flexible pavements fail due to rutting in the asphalt layer, while thin flexible pavements fail due to fatigue cracking. Therefore, the LEFs were developed in this study for two load-related failure mechanisms, rutting for thick asphalt pavements and fatigue cracking for thin asphalt pavements, respectively. The top-down cracking is not included considering that it is a combined effect of loading and thermal stress and the influence of tire-pavement interaction was not captured in the current version of Pavement-ME (Wang, Al-Qadi 2009).

Fig. 1 compares the LEFs from AASHO road test $\left(S N=5, P S I_{t}=2.5\right)$ and the M-E based LEFs for fatigue cracking and rutting, respectively. The pavement structures used in the analysis are the thin pavement for fatigue cracking and the thick pavement for rutting, as shown in Table 1. As expected, the potential of fatigue cracking in thin asphalt pavements are more sensitive to the load change compared to the potential of primary rutting in thick asphalt pavements. The results show that that for single axle the LEFs for fatigue cracking calculated from the M-E approach are close to the clas-
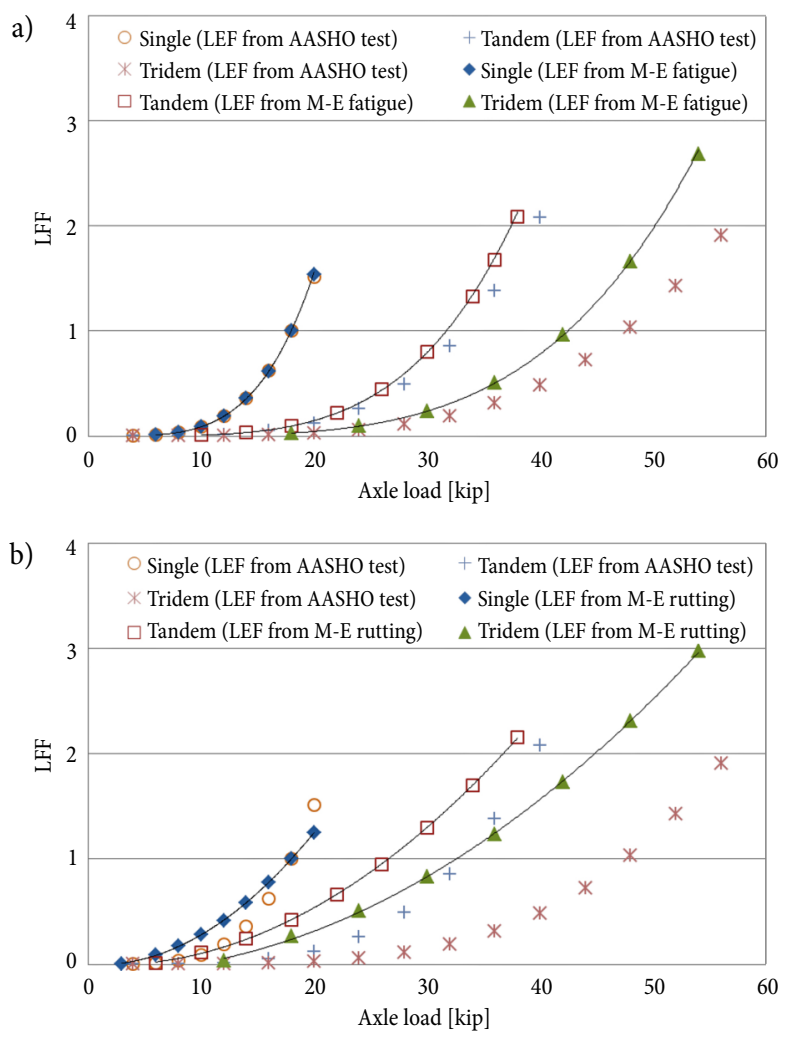

Fig. 1. Load equivalency factors (LEFs) for (a) fatigue cracking and (b) asphalt layer rutting as compared to lefs from 1993 AASHTO method sic LEFs from AASHO road test. On the other hand, for single axles the LEFs for rutting calculated from the M-E analysis are greater than the classical LEFs when the axle load is smaller than $18 \mathrm{kips}$, but become smaller than the classical LEFs when the axle load is greater than 18 kips. However, the classic LEFs underestimate the impact of multi-axle load on pavement damage compared to the LEFs calculated from the M-E analysis and the difference is more significant for the case of rutting. These differences were originated from the determination of the allowable number of load repetitions until failure; the present serviceability in the AASHO road test and the specific failure criteria of fatigue cracking or rutting.

\subsection{Derivation of Marginal Pavement Damage Cost}

The first step in calculating MPDC is to develop pavement cost function with respect to road usage, such as the number of ESALs. Several alternative regression functions were investigated to build models of cost functions. Considering the relatively high $\mathrm{R}$-squares ranging from 0.97 to 0.99 , the exponent function was selected as the function of EUAC with respect to the annual ESALs, as shown in Eq. (7):

$$
E U A C=\beta_{0} \cdot e^{\beta_{1} \cdot \log _{10}(E S A L s)},
$$

where: $\beta_{0}, \beta_{1}$ are parameter estimates for model explanatory variables; EUAC is EUAC/lane-mile over analysis period; ESALs are average annual number of Equivalent Single Axle Load per lane-mile.

MPDC is defined as a unit cost of providing pavement structure for one additional passage of a unit road usage expressed as ESAL. Compared to average damage cost, it is more realistic and practical method to calculate pavement damage cost. The estimated MPDC functions were differentiated with respect to average annual EASLs to obtain MPDC, as shown in Eq. (8):

$$
M P D C=\frac{\beta_{0} \cdot \beta_{1}}{\ln (10)} \cdot(E S A L s)\left(\frac{\beta_{1}}{\ln (10)}-1\right),
$$

where: $M P D C$ is Marginal Pavement Damage Cost [\$/ESAL-mile]; ESALs are average annual number of ESAL/lane-mile.

Figs 2 and 3 show the calculated MPDC with different LCCA parameters, respectively, for thick and thin asphalt pavements. The pavement damage cost decreases as the number of ESALs increases that could be caused by the increase of traffic volume or truck weights. This clearly indicates the variation of MPDC with traffic loading conditions. It was found that, full reconstruction strategy caused a significant increase in MPDC. As expected, a shorter analysis period or a higher discount rate leads to a lower MPDC. However, the effect of discount rate was found not significant. MPDC is more sensitive to analysis period than discount rate. It should be noted that the MPDC of thick asphalt pavements is about 10 times that of thin asphalt pavements. This clearly indicates that heavy loaded trucks will cause much more damage on minor and local roads with relatively thin asphalt layers. 

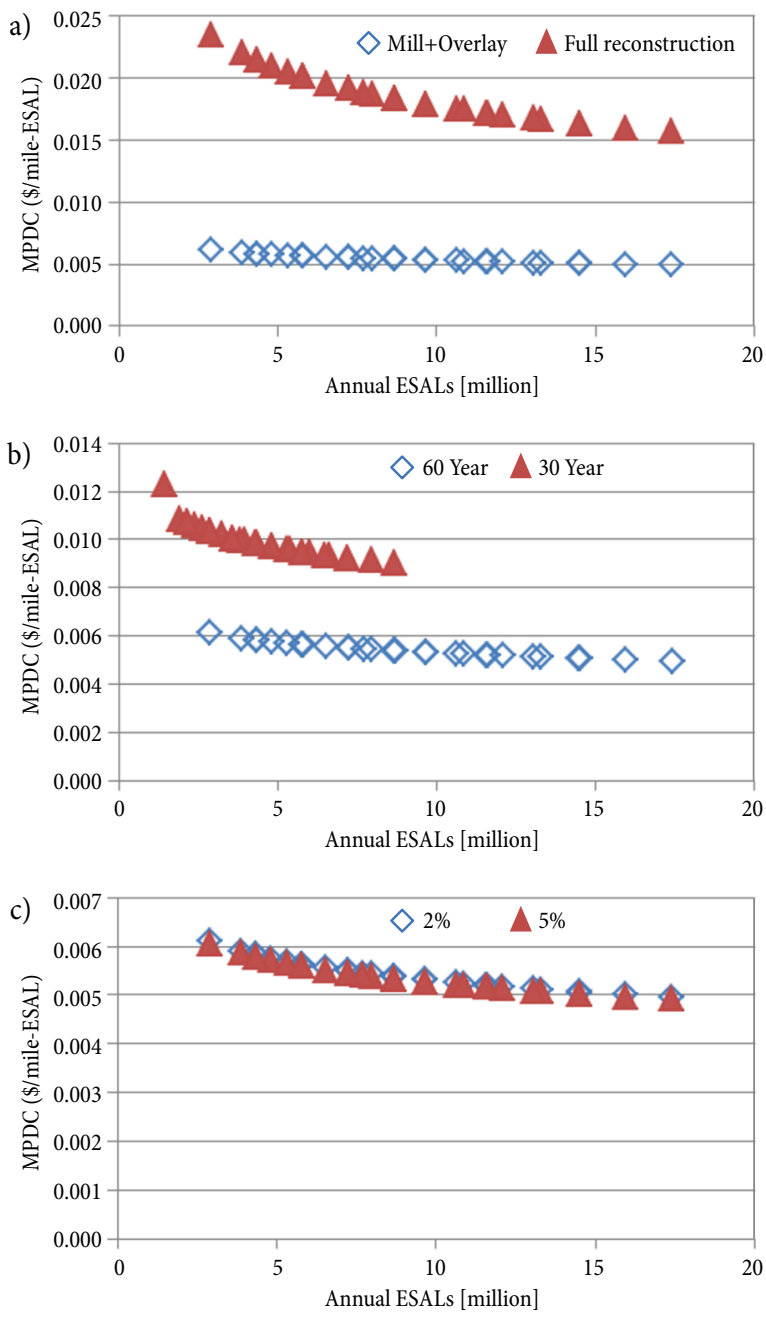

Fig. 2. Effect of LCCA parameters on MPDC of thick asphalt pavements: $a$ - maintenance strategy; $b$ - analysis period; $c$ - discount rate

\section{Development of Overweight Permit Fee}

\subsection{Framework to Determine Permit Fee}

After the LEFs and the MPDC are known, the pavement damage cost caused by an individual truck can be estimated using Eq. (9). In this case, the pavement damage caused by an individual truck with a combination of different axles is equivalent to the linear combination of the damage caused by each axle. The LEFs were used to provide a universal approach for calculation of load equivalency for any given truck configuration.

Cost per truck-mile $=\sum_{i=1}^{k} L E F_{i} \cdot M P D C[\$ / E S A L-m i l e]$,

where: $L E F_{i}$ is LEF for each axle group; $k$ is number of axle groups for the truck.

The ideal permit fee structure should be based on the axle loading and configuration and use the actual pavement damage cost caused by the overweight axles using Eq. (9). In this case, it will be the axle-weightdistance based permit fee structure. Although the ideal permit fee structure considers the fairness between
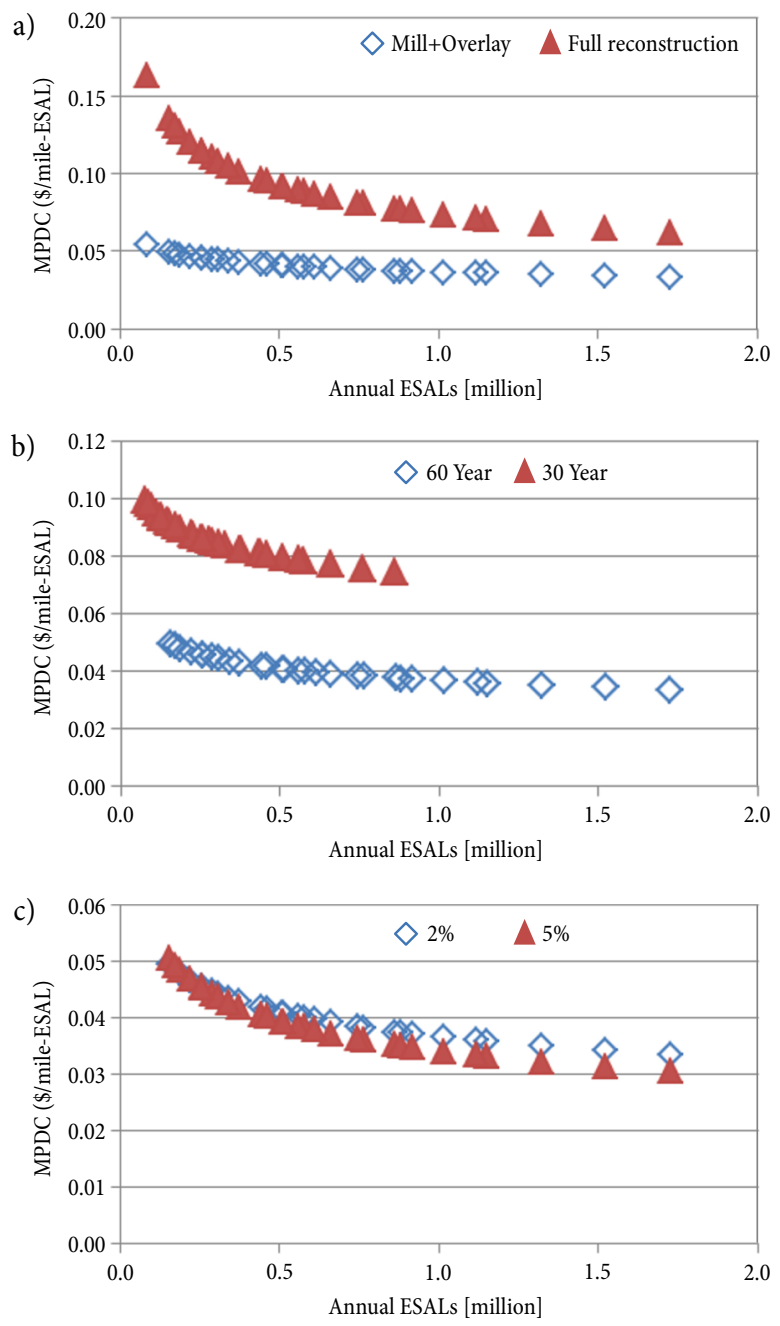

Fig. 3. Effect of LCCA parameters MPDC of thin asphalt pavements: $\mathrm{a}$ - maintenance strategy; $\mathrm{b}$ - analysis period; $c$ - discount rate

different truck classes, it will increase the difficulty of implementation in practice. This study focused on the determination of weight-based permit fee that is based on the total overweight tonnage.

The extra pavement damage cost caused by overweight truck is due to the tonnage exceeding the legal weight limits. Thus, the original traffic with overweight trucks should be modified by removing the excessive weight on overweight trucks. The pavement cost difference between the original traffic (overweight trucks with original weights) and the modified traffic (overweight trucks with legal weight limits) can be calculated. Therefore, if it is assumed that the revenue from permit fee is able to recover the extra pavement damage cost caused by all overweight truck trips, permit fee that should be charged on overweight trucks can be determined.

Fig. 4 provides a conceptual framework of developing overweight permit fee for different fee structures. Seven steps are included in this process:

- Step 1: Collect truck configurations from WIM stations. Then axle loads and GVW of truck configurations at each truck classification for an entire year are obtained. 
- Step 2: Modify the weight of overweight trucks in the original traffic stream through removing tonnage exceeding legal weight limits, after which, overweight tonnage can be estimated.

- Step 3: Based on axle load type (single, tandem, tridem, or quad) and failure mechanism (fatigue cracking or rutting), select corresponding LEF fitting functions to calculate the annual ESALs.

- Step 4: Use EUAC regression models to determine EUAC [ $\$ / \mathrm{mile}]$ of the original traffic and the modified traffic, respectively. Subtract EUAC [\$/mile] of modified traffic from EUAC of original traffic to obtain the EUAC difference [\$/mile] resulted from total overweight tonnage.

- Step 5: Multiply VMT of overweight trucks by the EUAC difference [\$/mile]. The result represents the EUAC difference [\$] caused by all overweight trucks on an individual route.

- Step 6: Accumulate the EUAC difference [\$] and the total VMT of overweight trucks in the highway network. Divide the total EUAC difference [\$] on all routes by the total VMT of overweight trucks in the highway network to obtain the average EUAC difference [ $\$ / \mathrm{mile}]$.

- Step 7: Calculate permit fees using Eqs (10-13), respectively, for distance based, weight and distance based, weight based, and flat permit fee:

Distance base permit fee $=\frac{\Delta E U A C}{n}$;

Weight and distance based permit fee $=\frac{\Delta E U A C}{w}$;

Weight based permit fee $=\frac{\Delta E U A C}{w} \cdot l$;

Flat permit fee $=\frac{\triangle E U A C}{n} \cdot l$,

where: $\triangle E U A C$ is the average EUAC in the highway network [\$/mile]; $n$ is the total number of overweight trucks in one year; $w$ is the total overweight tonnage exceeding legal limit [ton]; $l$ is average mileage traveled by overweight trucks per trip.

\subsection{Permit Fees for Major and Local Roads}

In this analysis, permit fee was determined for major and local road network, respectively. In order to illustrate the calculation process in a simplified way, only one road was considered at each road network with the thick and thin asphalt pavement structure analyzed above. The legal weight limits legislated by the New Jersey Department of Transportation was used, which include the GVW of $80000 \mathrm{lbs}$, the axle weight of $22400 \mathrm{lbs}$ on a single axle, and the axle weight of $34000 \mathrm{lbs}$ on a tandem axle. In addition, Bridge Formula weight limits were utilized to limit the maximum weight on any set of axles on a truck (DoT 2000).

The examples of modifying the typical overweight trucks of each truck classification were shown in Tables 2 and 3, respectively, for thick and thin asphalt pavements. The axle configuration and loading of typi-

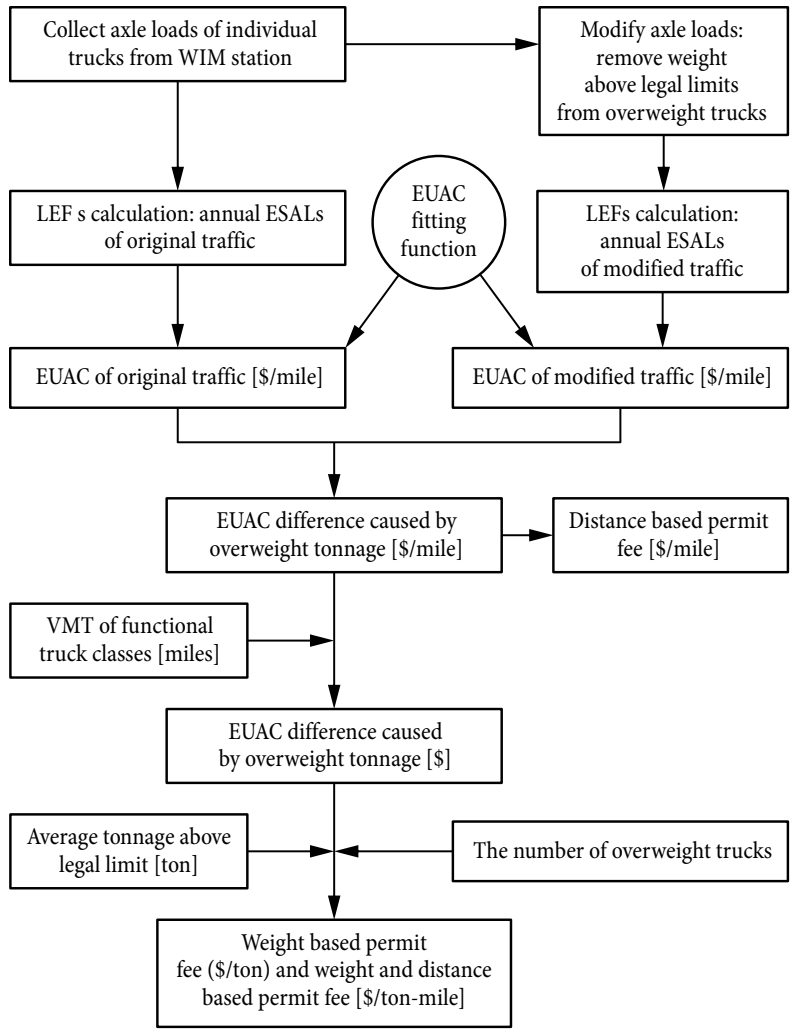

Fig. 4. Framework of determination of permit fee for overweight trucks using Marginal Pavement Damage Cost (MPDC)

cal overweight trucks were obtained from the WIM data. The LEFs determined from M-E analysis (as shown in Fig. 1) were used to calculate the total equivalent ESALs of each truck before and after overweight adjustment. The same overweight adjustment was applied for all the overweight trucks on I-78 (thick asphalt pavement) and NJ-55 (thin asphalt pavement). The average overweight tonnage per truck on I-78 was found 3.20 ton, and the average overweight tonnage per truck on NJ-55 was found 5.91 ton. It is noted that the developed methodology can be applied to different definitions of traffic classes if the axle configuration of each traffic class is known.

The LCCA results with $2 \%$ discount rate during a 60 -year analysis period using rehabilitation strategy were used to determine the additional EUAC resulted from the total overweight tonnage. With the calculated annual ESALs, the EUAC difference between the original and modified traffic can be determined, respectively, for thick and thin asphalt pavements, as shown in Fig. 5.

The calculation results indicate that the distance based permit fee is $\$ 0.0102 /$ mile per truck for thick asphalt pavements and $\$ 0.168 /$ mile per truck for thin asphalt pavements. On the other hand, the weight and distance based permit fee is $\$ 0.0032 /$ mile-ton for thick asphalt pavements and $\$ 0.0283 / \mathrm{mile}$-ton for thin asphalt pavements. The weight based permit fee and flat permit fee can be calculated if the average mileage traveled by overweight trucks per trip is known. 

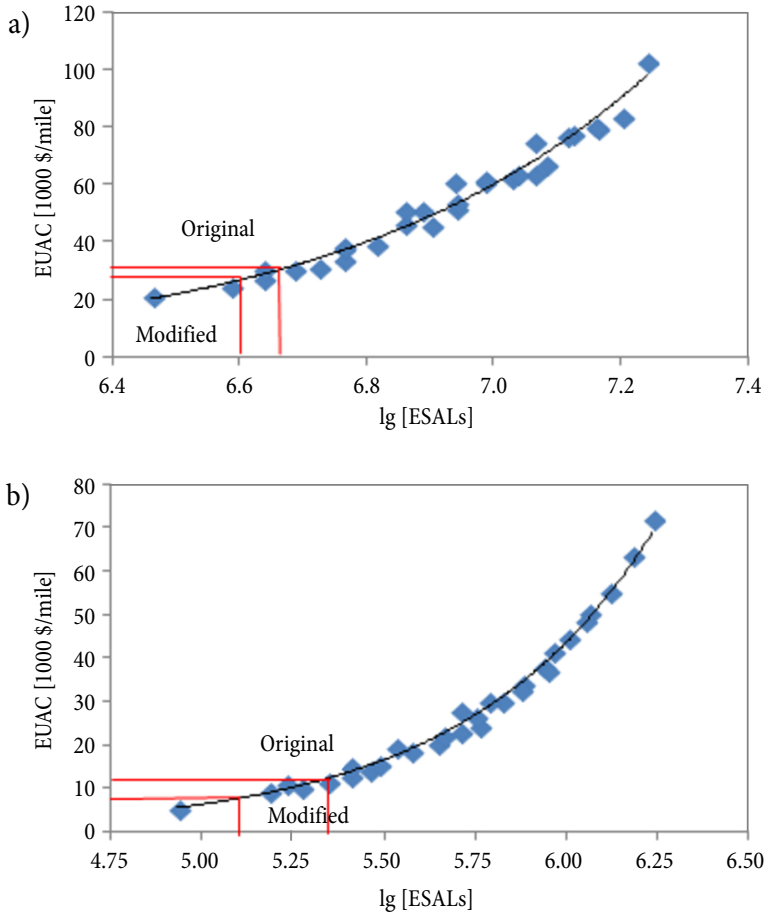

Fig. 5. EUAC differences between original traffic and modified traffic for: a - thick asphalt pavement; $\mathrm{b}$ - thin asphalt pavements

It is noted that the permit fee here was determined based on the assumption that the total permit fee is equal to the extra pavement damage cost caused by all overweight trucks. This indicates that the permit may not be fair for all the overweight trucks. Tables 4 and 5 present comparisons of permit fees and the extra pavement damage cost caused by typical overweight trucks at each truck classification, respectively, for thick and thin asphalt pavements. The trucks have the axle loads and axle configurations as shown in Tables 2 and 3. The extra pavement damage cost was computed using the MPDC obtained from Eq. (9), where the LEFs were calculated from the overweight tonnage of the individual truck. The results show that the weight and distance based permit fee has better agreements with the extra pavement damage cost caused by overweight tonnage, as compared to the distance based permit fee. However, the specific permit fee charged for the individual overweigh truck may be greater or smaller than the extra pavement damage cost caused by the overweight tonnage carried by the individual truck, depending on axle loads and axle configurations.

\section{Discussions and Limitations}

Since the focus of this study is to develop the methodology for determining permit fee considering pavement damage cost caused by truck loading, the study is limited to use the nationally calibrated performance transfer functions and the default failure thresholds recommended in the Pavement-ME. Although the calibration parameters and failure thresholds may affect the estimation of pavement life and the derived cost values, the developed methodology can be still applied. Further study is needed to implement the developed methodology with local calibration of MEDPG by agencies. Quality control of WIM data need to be conducted in future study to assure no missing data on certain axle groups of trucks.

Table 2. Examples of modifying overweight truck traffic on thick asphalt pavements

\begin{tabular}{|c|c|c|c|c|c|c|c|c|c|c|c|c|c|c|c|c|c|c|c|c|}
\hline Truck Class & \multicolumn{2}{|c|}{ Class 4} & \multicolumn{2}{|c|}{ Class 5} & \multicolumn{2}{|c|}{ Class 6} & \multicolumn{2}{|c|}{ Class 7} & \multicolumn{2}{|c|}{ Class 8} & \multicolumn{2}{|c|}{ Class 9} & \multicolumn{2}{|c|}{ Class 10} & \multicolumn{2}{|c|}{ Class 11} & \multicolumn{2}{|c|}{ Class 12} & \multicolumn{2}{|c|}{ Class 13} \\
\hline Traffic ${ }^{*}$ & 1 & 2 & 1 & 2 & 1 & 2 & 1 & 2 & 1 & 2 & 1 & 2 & 1 & 2 & 1 & 2 & 1 & 2 & 1 & 2 \\
\hline GVW [kip] & 37.4 & 35.4 & 53.7 & 44 & 47.3 & 44.1 & 63.2 & 44.24 & 73.7 & 51.3 & 114.8 & 80 & 86.8 & 80 & 83.6 & 80 & 105 & 80 & 134.2 & 80 \\
\hline \multirow{5}{*}{$\begin{array}{l}\text { Single axle } \\
\text { [kip] }\end{array}$} & 13 & 13 & 21.6 & 21.6 & 10.1 & 10.1 & 11.2 & 10.34 & 6.1 & 6.1 & 17.6 & 12 & 26.2 & 19.4 & 11.2 & 11.2 & 12.7 & 9.1 & 18.2 & 9.8 \\
\hline & 24.4 & 22.4 & 32.1 & 22.4 & & & & & 11.2 & 11.2 & & & & & 18.2 & 18.2 & 20.2 & 16.5 & 15.6 & 6.6 \\
\hline & & & & & & & & & & & & & & & 18.5 & 18.5 & 17.6 & 14 & & \\
\hline & & & & & & & & & & & & & & & 15.2 & 15.2 & 17.8 & 6.4 & & \\
\hline & & & & & & & & & & & & & & & 20.5 & 16.9 & & & & \\
\hline \multirow{2}{*}{$\begin{array}{l}\text { Tandem } \\
\text { axle [kip] }\end{array}$} & & & & & 37.2 & 34 & & & 56.4 & 34 & 49.5 & 34 & 28.1 & 28.1 & & & 36.7 & 34 & 30.1 & 21.1 \\
\hline & & & & & & & & & & & 47.7 & 34 & & & & & & & & \\
\hline $\begin{array}{l}\text { Tridem axle } \\
\text { [kip] }\end{array}$ & & & & & & & 52 & 33.9 & & & & & 32.5 & 32.5 & & & & & & \\
\hline $\begin{array}{l}\text { Quad axle } \\
\text { [kip] }\end{array}$ & & & & & & & & & & & & & & & & & & & 70.3 & 42.9 \\
\hline $\begin{array}{l}\text { Total } \\
\text { equivalent } \\
\text { ESALs }\end{array}$ & 2.67 & 2.23 & 6.14 & 3.42 & 2.43 & 1.98 & 3.27 & 1.20 & 6.59 & 1.91 & 9.74 & 3.86 & 4.60 & 3.16 & 4.52 & 3.97 & 5.86 & 3.34 & 6.42 & 1.71 \\
\hline $\begin{array}{l}\text { Overweight } \\
\text { [kip] }\end{array}$ & \multicolumn{2}{|c|}{2} & \multicolumn{2}{|c|}{9.7} & \multicolumn{2}{|c|}{3.2} & \multicolumn{2}{|c|}{18.96} & \multicolumn{2}{|c|}{22.4} & \multicolumn{2}{|c|}{34.8} & \multicolumn{2}{|c|}{6.8} & \multicolumn{2}{|c|}{3.6} & \multicolumn{2}{|c|}{25} & \multicolumn{2}{|c|}{53.8} \\
\hline
\end{tabular}

Note: ${ }^{\star}-1$ indicates the original traffic; 2 indicates the modified traffic without overweight tonnage. 
Table 3. Examples of modifying overweight truck traffic on thin asphalt pavements

\begin{tabular}{|c|c|c|c|c|c|c|c|c|c|c|c|c|c|c|c|c|c|c|c|c|}
\hline \multirow{2}{*}{$\begin{array}{l}\text { Truck Class } \\
\text { Traffic }^{\star}\end{array}$} & \multicolumn{2}{|c|}{ Class 4} & \multicolumn{2}{|c|}{ Class 5} & \multicolumn{2}{|c|}{ Class 6} & \multicolumn{2}{|c|}{ Class 7} & \multicolumn{2}{|c|}{ Class 8} & \multicolumn{2}{|c|}{ Class 9} & \multicolumn{2}{|c|}{ Class 10} & \multicolumn{2}{|c|}{ Class 11} & \multicolumn{2}{|c|}{ Class 12} & \multicolumn{2}{|c|}{ Class 13} \\
\hline & 1 & 2 & 1 & 2 & 1 & 2 & 1 & 2 & 1 & 2 & 1 & 2 & 1 & 2 & 1 & 2 & 1 & 2 & 1 & 2 \\
\hline GVW [kip] & 37.4 & 35.4 & 53.7 & 44 & 47.3 & 44.1 & 63.2 & 44.24 & 73.7 & 51.3 & 114.8 & 80 & 86.8 & 80 & 83.6 & 80 & 105 & 80 & 134.2 & 80 \\
\hline \multirow{5}{*}{$\begin{array}{l}\text { Single axle } \\
\text { [kip] }\end{array}$} & 13 & 13 & 21.6 & 21.6 & 10.1 & 10.1 & 11.2 & 10.34 & 6.1 & 6.1 & 17.6 & 12 & 26.2 & 19.4 & 11.2 & 11.2 & 12.7 & 9.1 & 18.2 & 9.8 \\
\hline & 24.4 & 22.4 & 32.1 & 22.4 & & & & & 11.2 & 11.2 & & & & & 18.2 & 18.2 & 20.2 & 16.5 & 15.6 & 6.6 \\
\hline & & & & & & & & & & & & & & & 18.5 & 18.5 & 17.6 & 14 & & \\
\hline & & & & & & & & & & & & & & & 15.2 & 15.2 & 17.8 & 6.4 & & \\
\hline & & & & & & & & & & & & & & & 20.5 & 16.9 & & & & \\
\hline \multirow{2}{*}{$\begin{array}{l}\text { Tandem } \\
\text { axle [kip] }\end{array}$} & & & & & 37.2 & 34 & & & 56.4 & 34 & 49.5 & 34 & 28.1 & 28.1 & & & 36.7 & 34 & 30.1 & 21.1 \\
\hline & & & & & & & & & & & 47.7 & 34 & & & & & & & & \\
\hline $\begin{array}{l}\text { Tridem axle } \\
\text { [kip] }\end{array}$ & & & & & & & 52 & 33.9 & & & & & 32.5 & 32.5 & & & & & & \\
\hline $\begin{array}{l}\text { Quad axle } \\
\text { [kip] }\end{array}$ & & & & & & & & & & & & & & & & & & & 70.3 & 42.9 \\
\hline $\begin{array}{l}\text { Total } \\
\text { equivalent } \\
\text { ESALs }\end{array}$ & 3.96 & 2.86 & 13.63 & 4.81 & 2.07 & 1.45 & 2.67 & 0.54 & 11.25 & 1.52 & 12.94 & 2.91 & 5.91 & 2.41 & 4.74 & 3.76 & 5.76 & 2.54 & 5.93 & 0.74 \\
\hline $\begin{array}{l}\text { Overweight } \\
\text { [kip] }\end{array}$ & 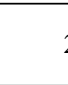 & 2 & 9. & & 3. & & & 96 & 22 & & 34 & .8 & 6. & & 3. & & & 5 & 5 & 4 \\
\hline
\end{tabular}

Note: ${ }^{\star}-1$ indicates the original traffic; 2 indicates the modified traffic without overweight tonnage.

Table 4. Comparison of permit fee structures for thick asphalt pavements

\begin{tabular}{|l|c|c|c|c|c|c|c|c|c|c|}
\hline \multicolumn{1}{|c|}{ Truck class } & Class 4 & Class 5 & Class 6 & Class 7 & Class 8 & Class 9 & Class 10 & Class 11 & Class 12 & Class 13 \\
\hline Overweight tonnage & 1.00 & 4.85 & 1.60 & 9.48 & 11.20 & 17.40 & 3.40 & 1.80 & 12.50 & 26.90 \\
\hline Extra ESALs & 0.44 & 2.72 & 0.46 & 2.08 & 4.68 & 5.88 & 1.44 & 0.56 & 2.52 & 4.71 \\
\hline $\begin{array}{l}\text { Distance based permit } \\
\text { fee [\$/mile] }\end{array}$ & 0.0102 & 0.0102 & 0.0102 & 0.0102 & 0.0102 & 0.0102 & 0.0102 & 0.0102 & 0.0102 & 0.0102 \\
\hline $\begin{array}{l}\text { Weight and distance } \\
\text { based permit } \\
\text { fee } \times \text { Overweight } \\
\text { tonnage [\$/mile] }\end{array}$ & 0.003 & 0.016 & 0.005 & 0.030 & 0.036 & 0.056 & 0.011 & 0.006 & 0.040 & 0.086 \\
\hline $\begin{array}{l}\text { Extra pavement } \\
\text { damage cost [\$/mile] }\end{array}$ & 0.003 & 0.022 & 0.004 & 0.016 & 0.037 & 0.047 & 0.011 & 0.004 & 0.020 & 0.037 \\
\hline
\end{tabular}

Table 5. Comparison of permit fee structures for thin asphalt pavements

\begin{tabular}{|l|c|c|c|c|c|c|c|c|c|c|}
\hline \multicolumn{1}{|c|}{ Truck class } & Class 4 & Class 5 & Class 6 & Class 7 & Class 8 & Class 9 & Class 10 & Class 11 & Class 12 & Class 13 \\
\hline Overweight tonnage & 1.00 & 4.85 & 1.60 & 9.48 & 11.20 & 17.40 & 3.40 & 1.80 & 12.50 & 26.90 \\
\hline Extra ESALs & 0.44 & 2.72 & 0.46 & 2.08 & 4.68 & 5.88 & 1.44 & 0.56 & 2.52 & 4.71 \\
\hline $\begin{array}{l}\text { Distance based permit } \\
\text { fee [\$/mile] }\end{array}$ & 0.168 & 0.168 & 0.168 & 0.168 & 0.168 & 0.168 & 0.168 & 0.168 & 0.168 & 0.168 \\
\hline $\begin{array}{l}\text { Weight and distance } \\
\text { based permit } \\
\text { fee } \times \text { Overweight } \\
\text { tonnage [\$/mile] }\end{array}$ & 0.024 & 0.115 & 0.038 & 0.226 & 0.267 & 0.414 & 0.081 & 0.043 & 0.298 & 0.640 \\
\hline $\begin{array}{l}\text { Extra pavement } \\
\text { damage cost [\$/mile] }\end{array}$ & 0.051 & 0.409 & 0.029 & 0.099 & 0.452 & 0.465 & 0.163 & 0.046 & 0.150 & 0.241 \\
\hline
\end{tabular}




\section{Conclusions}

This study proposed a methodology for developing overweight permit fees, which could be charged by highway agencies to recover additional pavement damage cost caused by overweight trucks. If complete WIM data for a whole year and miles traveled by overweight trucks are available, the methodology framework can be applied to the highway network to determine overweight permit fee with distance based, weight and distance based, weight based, and flat fee structures.

With the local traffic and pavement data in New Jersey, example permit fees were determined for the major and local road network with the thick and thin asphalt pavement structure, respectively. The following conclusions were concluded from the analysis:

- Exponential relationships between the EUAC and the logarithm of average annual ESALs were found appropriate to derive MPDC functions.

- The sensitivity analysis in the LCCA revealed that repair strategy and analysis period have significant effects on MPDC, while slight cost changes were resulted from the change of discount rate.

- The actual pavement damage cost caused by overweight trucks varies significantly for thin and thick asphalt pavements, considering different failure mechanisms in fatigue cracking and rutting, respectively. This indicates that permit fee should be set for different road categories.

- If the permit fee is regulated to recover the extra pavement damage cost caused by all overweight trucks in the road network but the axle configuration is not considered in the permit fee structure, the permit fee may not represent the pavement damage cost caused by the excessive tonnage carried by the individual overweight truck in a fair way.

\section{References}

AASHTO. 1993. Guide for Design of Pavement Structures. American Association of State Highway and Transportation Officials (AASHTO), Washington, DC.

Adams, T.; Perry, E.; Schwartz, A.; Gollnik, B.; Kang, M.; Bittner, J.; Wagner, S. 2013. Aligning Oversize/Overweight Fees with Agency Costs: Critical Issues. Report CFIRE 0317. Wisconsin Department of Transportation, Madison, Wisconsin. 106 p. Available from Internet: http://wisconsindot.gov/documents2/research/WisDOT-CFIRE-project0092-10-21-final-report.pdf

Ahmed, A. 2012. Pavement Damage Cost Estimation Using Highway Agency Maintenance, Rehabilitation, and Reconstruction Strategies: Doctoral Dissertation. Purdue University, US. 340 p.

Banerjee, A.; Prozzi, J.; Buddhavarapu, P. 2013. Framework for determining load equivalencies with DARWin-ME, Transportation Research Record: Journal of the Transportation Research Board 2368: 24-35. http://doi.org/10.3141/2368-03

Bennert, T. 2009. Dynamic Modulus of Hot Mix Asphalt. Final Report FHWA-NJ-2009-011. Federal Highway Administration, US Department of Transportation, Washington, DC. $81 \mathrm{p}$.
Chowdhury, M.; Putman, B.; Pang, W.; Dunning, A.; Dey, K.; Chen, L. 2013. Rate of Deterioration of Bridges and Pavements as Affected by Trucks. Report FHWA-SC-13-05. South Carolina Department of Transportation, Columbia, SC. $353 \mathrm{p}$.

Dell'Acqua, G.; De Luca, M.; Lamberti, R. 2011. Indirect skid resistance measurement for porous asphalt pavement management, Transportation Research Record: Journal of the Transportation Research Board 2205: 147-154.

http://doi.org/10.3141/2205-19

Dell'Acqua, G.; De Luca, M.; Russo, F. 2012. Procedure for making paving decisions with cluster and multicriteria analysis, Transportation Research Record: Journal of the Transportation Research Board 2282: 57-66. http://doi.org/10.3141/2282-07

Dell'Acqua, G.; Russo, F. 2011. Road performance evaluation using geometric consistency and pavement distress data, Transportation Research Record: Journal of the Transportation Research Board 2203: 194-202. http://doi.org/10.3141/2203-24

DoT. 2000. Comprehensive Truck Size and Weight Study. FHWA-PL-00-029. US Department of Transportation (DoT). Washington, DC. Available from Internet: https://www. fhwa.dot.gov/reports/tswstudy/TSWfinal.htm

Hajek, J.; Tighe, S.; Hutchinson, B. 1998. Allocation of pavement damage due to trucks using a marginal cost method, Transportation Research Record: Journal of the Transportation Research Board 1613: 50-56. http://doi.org/10.3141/1613-07

Hallin, J. P.; Sadasivam, S.; Mallela, J.; Hein, D. K.; Darter, M. I.; Von Quintus, H. L. 2011. Guide for Pavement-Type Selection. National Cooperative Highway Research Program (NCHRP) Report 703. Transportation Research Board, Washington, DC. 81 p. Available from Internet: http://onlinepubs.trb.org/onlinepubs/nchrp/nchrp_rpt_703.pdf

Hewitt, J.; Stephens, J.; Smith, K.; Menuez, N. 1999. Infrastructure and economic impacts of changes in truck weight regulations in Montana, Transportation Research Record: Journal of the Transportation Research Board 1653: 42-51. http://doi.org/10.3141/1653-06

OMB. 1992. Circular A-94: Guidelines and Discount Rates for Benefit-Cost Analysis of Federal Programs. Office of Management and Budget (OMB). Available from Internet: http://www.whitehouse.gov/omb/circulars_a094

Prozzi, J.; Murphy, M.; Loftus-Otway, L.; Banerjee, A.; Kim, M.; Wu, H.; Prozzi, J. P.; Hutchison, R.; Harrison, R.; Walton, C. M.; Weissmann, J.; Weissmann, A. 2012. Oversize/ Overweight Vehicle Permit Fee Study. Report FHWA/TX13/0-6736-2. Texas Department of Transportation, Austin, TX. 392 p. Available from Internet: http://www.utexas.edu/ research/ctr/pdf_reports/0_6736_2.pdf

Tirado, C.; Carrasco, C.; Mares, J.; Gharaibeh, N.; Nazarian, S.; Bendaña, J. 2010. Process to estimate permit costs for movement of heavy trucks on flexible pavements, Transportation Research Record: Journal of the Transportation Research Board 2154: 187-196. http://doi.org/10.3141/2154-19

TRB. 2004. Development of the 2002 Guide for the Design of New and Rehabilitated Pavement Structures. Report NCHRP 01-37A. Transportation Research Board (TRB), Washington, DC.

Walls, J.; Smith, M. R. 1998. Life-Cycle Cost Analysis in Pavement Design: in Search of Better Investment Decisions. Final Report FHWA-SA-98-079. Federal Highway Administration, US Department of Transportation, Washington, DC. 
123 p. Available from Internet: https://www.fhwa.dot.gov/ infrastructure/asstmgmt/013017.pdf

Wang, H.; Al-Qadi, I. L. 2009. Combined effect of moving wheel loading and three-dimensional contact stresses on perpetual pavement responses, Transportation Research Record: Journal of the Transportation Research Board 2095: 53-61. http://doi.org/10.3141/2095-06

Wang, H.; Al-Qadi, I. 2010. Near-surface pavement failure under multiaxial stress state in thick asphalt pavement, Transportation Research Record: Journal of the Transportation Research Board 2154: 91-99. http://doi.org/10.3141/2154-08

Wang, H.; Ozer, H.; Al-Qadi, I.; Duarte, C. 2013. Analysis of near-surface cracking under critical loading conditions using uncracked and cracked pavement models, Journal of Transportation Engineering 139(10): 992-1000.

http://doi.org/10.1061/(ASCE)TE.1943-5436.0000562

Zaghloul, S.; Helali, K.; Ahmed, Z.; Sauber, R.; Jumikis, A. 2006. Cash flow control of New Jersey interstate needs, Transportation Research Record: Journal of the Transportation Research Board 1974: 54-62. http://doi.org/10.3141/1974-09

Zhang, L. 2007. An Evaluation of the Technical and Economic Performance of Weigh-In-Motion Sensing Technology: MSc Thesis. University of Waterloo, Waterloo, Ontario, Canada. 144 p. Available from Internet: https://uwspace.uwaterloo. $\mathrm{ca} /$ handle/10012/3219

Žilionienè, D.; De Luca, M.; Dell'Acqua, G. 2013. Evaluation of climatic factors based on the mechanistic-empirical pavement design guide, The Baltic Journal of Road and Bridge Engineering 8(3): 158-165.

http://doi.org/10.3846/bjrbe.2013.20 